\title{
Assessing interactions between the associations of common genetic susceptibility variants, reproductive history and body mass index with breast cancer risk in the breast cancer association consortium: a combined case-control study
}

Roger L Milne ${ }^{1 *}$, Mia M Gaudet², Amanda B Spurdle³, Peter A Fasching ${ }^{4}$, Fergus J Couch ${ }^{5}$, Javier Benítez ${ }^{6}$, José Ignacio Arias Pérez", M Pilar Zamora ${ }^{8}$, Núria Malats', Isabel dos Santos Silva9 , Lorna J Gibson?', Olivia Fletcher ${ }^{10}$, Nichola Johnson ${ }^{10}$, Hoda Anton-Culver ${ }^{11}$, Argyrios Ziogas ${ }^{11}$, Jonine Figueroa ${ }^{12}$, Louise Brinton ${ }^{12}$, Mark E Sherman ${ }^{12}$, Jolanta Lissowska ${ }^{13}$, John L Hopper ${ }^{14}$, Gillian S Dite ${ }^{14}$, Carmel Apicella ${ }^{14}$, Melissa C Southey ${ }^{15}$, Alice J Sigurdson ${ }^{16}$, Martha S Linet ${ }^{16}$, Sara J Schonfeld ${ }^{16}$, D Michal Freedman ${ }^{16}$, Arto Mannermaa ${ }^{17,18,19}$, Veli-Matti Kosma 17,18,19, Vesa Kataja ${ }^{20,21}$, Päivi Auvinen ${ }^{20}$, Irene L Andrulis ${ }^{22,23,24}$, Gord Glendon ${ }^{23}$, Julia A Knight ${ }^{22,25}$, Nayana Weerasooriya ${ }^{23}$, Angela Cox ${ }^{26}$, Malcolm WR Reed ${ }^{27}$, Simon S Cross ${ }^{28}$, Alison M Dunning ${ }^{29}$, Shahana Ahmed ${ }^{29}$, Mitul Shah ${ }^{29}$, Hiltrud Brauch ${ }^{30}$, Yon-Dschun Ko ${ }^{31}$, Thomas Brüning ${ }^{32}$, GENICA Network ${ }^{30,31,32,33,34}$, Diether Lambrechts ${ }^{35}$, Joke Reumers ${ }^{35}$, Ann Smeets ${ }^{36}$, Shan Wang-Gohrke ${ }^{37}$, Per Hall ${ }^{38}$, Kamila Czene ${ }^{38}$, Jianjun Liu ${ }^{39}$, Astrid K Irwanto ${ }^{39}$, Georgia Chenevix-Trench ${ }^{3}$, Helene Holland ${ }^{3}$, kConFab ${ }^{40}$, AOCS ${ }^{3,41}$, Graham G Giles ${ }^{14,42,43}$, Laura Baglietto ${ }^{14,42}$, Gianluca Severi ${ }^{14,42}$, Stig E Bojensen ${ }^{44}$, Børge G Nordestgaard ${ }^{44}$, Henrik Flyger ${ }^{44}$, Esther M John ${ }^{45,46}$, Dee W West ${ }^{45,46}$, Alice S Whittemore ${ }^{46}$, Celine Vachon ${ }^{47}$, Janet E Olson ${ }^{47}$, Zachary Fredericksen ${ }^{47}$, Matthew Kosel ${ }^{47}$, Rebecca Hein ${ }^{48}$, Alina Vrieling ${ }^{48}$, Dieter Flesch-Janys ${ }^{49}$, Judith Heinz ${ }^{49}$, Matthias W Beckmann ${ }^{50}$, Katharina Heusinger ${ }^{50}$, Arif B Ekici ${ }^{51}$, Lothar Haeberle ${ }^{50}$, Manjeet K Humphreys ${ }^{52}$, Jonathan Morrison ${ }^{52}$, Doug F Easton ${ }^{52}$, Paul D Pharoah ${ }^{29}$, Montserrat García-Closas ${ }^{12,29}$, Ellen L Goode ${ }^{47}$, Jenny Chang-Claude ${ }^{48}$

\footnotetext{
Abstract

Introduction: Several common breast cancer genetic susceptibility variants have recently been identified. We aimed to determine how these variants combine with a subset of other known risk factors to influence breast cancer risk in white women of European ancestry using case-control studies participating in the Breast Cancer Association Consortium.
}

Methods: We evaluated two-way interactions between each of age at menarche, ever having had a live birth, number of live births, age at first birth and body mass index (BMI) and each of 12 single nucleotide polymorphisms (SNPS) (10q26-rs2981582 (FGFR2), 8q24-rs13281615, 11p15-rs3817198 (LSP1), 5q11-rs889312 (MAP3K1), 16q12-rs3803662 (TOX3), 2q35-rs13387042, 5p12-rs10941679 (MRPS30), 17q23-rs6504950 (COX11), 3p24-rs4973768 (SLC4A7), CASP8-rs17468277, TGFB1-rs1982073 and ESR1-rs3020314). Interactions were tested

\footnotetext{
* Correspondence: rmilne@cnio.es

'Genetic and Molecular Epidemiology Group, Human Cancer Genetics Programme, Spanish National Cancer Research Centre (CNIO), Melchor Fernández Almagro 3, Madrid, 28029, Spain

Full list of author information is available at the end of the article
} 
for by fitting logistic regression models including per-allele and linear trend main effects for SNPs and risk factors, respectively, and single-parameter interaction terms for linear departure from independent multiplicative effects.

Results: These analyses were applied to data for up to 26,349 invasive breast cancer cases and up to 32,208 controls from 21 case-control studies. No statistical evidence of interaction was observed beyond that expected by chance. Analyses were repeated using data from 11 population-based studies, and results were very similar.

Conclusions: The relative risks for breast cancer associated with the common susceptibility variants identified to date do not appear to vary across women with different reproductive histories or body mass index (BMI). The assumption of multiplicative combined effects for these established genetic and other risk factors in risk prediction models appears justified.

\section{Introduction}

Breast cancer is known to have both a genetic and nongenetic etiology. Several common genetic susceptibility variants have recently been identified, predominantly by genome-wide association studies (GWAS). These include single nucleotide polymorphisms (SNPs) at loci containing the genes FGFR2, LSP1, MAP3K1, TOX3, MRPS30, COX 11, SLC4A7, and at chromosomes 8p24 and 2q35 [1-5]. To date, the only SNP associated with breast cancer risk with genome-wide statistical significance $\left(P<10^{-7}\right)$ coming from candidate gene approaches is CASP8 [6]; more equivocal evidence has been reported for SNPs in TGFB1 [6] and ESR1 [7], among others.

It is important to determine how these common SNPs combine with other known risk factors such as age at menarche, parity, age at first birth and body mass index (BMI) $[8,9]$ to influence breast cancer risk because this knowledge could be used to improve risk prediction models $[10,11]$. The identification of modification of SNP associations by other risk factors could also provide insight into the biological mechanisms by which genetic variants are implicated in breast cancer etiology. Many of these SNPs and other risk factors have been observed to be differentially associated with estrogen receptor (ER)-positive and ER-negative disease $[1,4,5,7,12,13]$ and so interactions between them may also differ by disease subtype.

We, therefore, aimed to assess effect modification for 12 SNPs, 10 of which have been clearly associated with breast cancer risk (10q26-rs298158 (FGFR2), 8q24rs13281615, 11p15-rs3817198 (LSP1), 5q11-rs889312 (MAP3K1), 16q12-rs2803662 (TOX3), 2q35-rs13387042, 5p12-rs10941679, 17q23-rs6504950, 3p24-rs4973768 and CASP8-rs17468277) and two for which there is less clear evidence of a main effect (TGFB1-rs1982073 and ESR1-rs3020314). The potential effect modifiers considered were age at menarche, ever having had a live birth, number of live births, age at first birth and BMI. A secondary aim was to evaluate these interactions in susceptibility to breast cancer subtypes defined by ER and progesterone receptor (PR) status. Data for white women of European ancestry were combined from 21 case-control studies participating in the Breast Cancer Association Consortium (BCAC).

\section{Materials and methods}

A description of the 21 case-control studies participating in this pooled BCAC analysis is provided in Table 1 , with more detailed information given in Additional Data Table S1 in Additional file 1. These included 11 population-based studies and seven studies with at least 1,000 cases and 1,000 controls. All studies collected selfreported information for cases and controls on age at diagnosis (cases) or interview (controls), racial/ethnic group (white European, Asian or other) and at least one of the following: age at menarche, ever having had a live birth, number of live births, age at first live birth (if parous), BMI (or height and weight). The time-point at which these variables were assessed for each study is detailed in Additional Data Table S1 in Additional file 1. Additional risk and other lifestyle factor information were not available at the time of the present analysis. All studies used structured questionnaires to collect these data, with the exception of the CNIO-BCS and the LMBC study, for which the information was abstracted from medical records. Nineteen studies also provided information on the ER and PR status of the tumors for a subset of cases. This information was mostly abstracted from medical records. Subjects who reported being of ethnicities other than white European were excluded, as were cases with non-invasive disease. All study participants gave written informed consent and each study was approved by the relevant local institutional review board(s).

Genotyping methods have been previously described $[1,6,7,12,14]$. Briefly, five studies (ABCFS, GENICA, kConFab/AOCS, MARIE and SASBAC) used Sequenom's MassARRAY system and iPLEX technology (Sequenom, San Diego, CA, USA) for most SNPs. All 
Table 1 List of participating studies and number of subjects included in at least one analysis

\begin{tabular}{|c|c|c|c|c|c|}
\hline $\begin{array}{l}\text { Study } \\
\text { Acronym }\end{array}$ & Study Name (Reference) & $\begin{array}{c}\mathrm{N} \\
\text { (Controls) }\end{array}$ & $\begin{array}{c}\mathrm{N} \\
\text { (Cases) }\end{array}$ & $N(E R+/-) \dagger$ & $\mathrm{N}(\mathrm{PR}+/-)+\dagger$ \\
\hline ABCFS* & Australian Breast Cancer Family Study [24] & 610 & 1,239 & $701 / 358$ & $731 / 325$ \\
\hline BBCC & Bavarian Breast Cancer Cases and Controls $[25,26]$ & 806 & 1,200 & $719 / 264$ & $640 / 341$ \\
\hline BBCS & British Breast Cancer Study [27] & 1,242 & 1,338 & $0 / 0$ & 0/0 \\
\hline $\mathrm{CGPS}^{*}$ & Copenhagen General Population Study $[28,29]$ & 6,555 & 1,450 & $1,088 / 213$ & $505 / 358$ \\
\hline CNIO-BCS & Spanish National Cancer Centre Breast Cancer Study [30] & 649 & 351 & $135 / 49$ & $113 / 87$ \\
\hline GENICA* & Gene Environment Interaction \& Breast Cancer in Germany [31] & 967 & 917 & $675 / 194$ & $607 / 260$ \\
\hline $\mathrm{GESBC}^{*}$ & Genetic Epidemiology Study of Breast Cancer by Age 50 [32] & 859 & 573 & 281/182 & 266/188 \\
\hline KBCP & Kuopio Breast Cancer Project [33] & 388 & 430 & $310 / 96$ & 253/151 \\
\hline $\begin{array}{l}\text { kConFab/ } \\
\text { AOCS }\end{array}$ & $\begin{array}{l}\text { Kathleen Cuningham Foundation Consortium for Research into Familial Breast Cancer } \\
\text { [34]/Australian Ovarian Cancer Study (controls only) [35] }\end{array}$ & 171 & 323 & $128 / 63$ & $122 / 48$ \\
\hline LMBC & Leuven Multidisciplinary Breast Centre $[36,37]$ & 804 & 818 & $624 / 137$ & $554 / 205$ \\
\hline MARIE* & Mammary Carcinoma Risk Factor Investigation [38] & 5,294 & 2,573 & $1,998 / 532$ & $1,681 / 847$ \\
\hline MCBCS & Mayo Clinic Breast Cancer Study [39] & 1,045 & 1,049 & $764 / 158$ & $673 / 244$ \\
\hline $\mathrm{MCCS}^{*}$ & Melbourne Collaborative Cohort Study [40] & 749 & 682 & $453 / 170$ & $351 / 272$ \\
\hline NC-BCFR* & Northern California Breast Cancer Family Registry [41] & 154 & 266 & $201 / 35$ & $172 / 63$ \\
\hline OFBCR* & Ontario Familial Breast Cancer Registry [41] & 328 & 982 & $578 / 228$ & $488 / 304$ \\
\hline $\mathrm{PBCS}^{*}$ & NCl Polish Breast Cancer Study [42] & 2,322 & 1,937 & $1,150 / 597$ & $916 / 827$ \\
\hline SASBAC* & Singapore and Sweden Breast Cancer Study [43] & 1,400 & 1,408 & $766 / 209$ & $679 / 276$ \\
\hline SBCS & Sheffield Breast Cancer Study [44] & 1,088 & 970 & $458 / 150$ & 170/107 \\
\hline SEARCH & Study of Epidemiology \& Risk factors in Cancer Heredity [45] & 5,282 & 6,352 & $3,438 / 816$ & $1,655 / 848$ \\
\hline UCIBCS* & UCI Breast Cancer Study $[46,47]$ & 465 & 795 & $512 / 131$ & 436/199 \\
\hline USRT & US Radiologic Technologists Study [48] & 1,030 & 696 & $0 / 0$ & $0 / 0$ \\
\hline
\end{tabular}

†Number of cases with estrogen receptor (ER) positive/negative disease, respectively, if known. $+\dagger$ Number of cases with estrogen receptor (PR) positive/negative disease, respectively, if known. *Population-based case-control study.

other genotyping was done using Taqman ${ }^{\circledR}$ Assays-byDesign $^{\text {SM }}$ (Applied Biosystems, Foster City, CA, USA). SNP CASP8- rs17468277 is in complete linkage disequilibrium with CASP8-rs1045485, which has previously been reported to be associated with breast cancer [6]. All studies included at least one blank well (containing no DNA) per 384-well assay plate, at least $2 \%$ of samples in duplicate, and a common set of 93 samples from the Centre d'Etude Polymorphisme Humain (CEPH) used by the HapMap Consortium (HAPMAPPT01, Coriell Institute for Medical Research, Camden, NJ, USA). Genotyping call rates and duplicate concordance rates were calculated after excluding samples that had previously repeatedly failed; all were greater than $95 \%$. Concordance with CEPH genotypes was greater than $98 \%$.

\section{Statistical methods}

Overall genetic associations were evaluated for each of the 12 SNPs by estimating odds ratios (ORs) and their 95\% confidence intervals (CI) via logistic regression, assuming multiplicative per-allele effects for the risk allele, as first reported in the literature (see Table 2). Main effects of risk factors were assessed only in the 11 population-based studies using logistic regression, adjusted for age (categorical: $\leq 34,35$ to 39,40 to 44,45 to 49,50 to 54,55 to 59,60 to 64,65 to 69,70 to 74 , $\geq 75$ years; and continuous, the latter to account for differences between cases and controls in the extreme agegroups) and study (categorical). Risk factors considered were age at menarche (categorical: $\leq 11,12,13,14, \geq 15$ years; and continuous), ever having had a live birth (no, yes), number of live births (parous women only, categorical: $1,2,3, \geq 4$; and continuous), age at first birth (parous women only, categorical: $\leq 19,20$ to 24,25 to 29 , $\geq 30$ years; and continuous) and BMI, defined as weight in kilograms divided by the square of height in meters (categorical: $\leq 24.99,25.00$ to 29.99 , $\geq 30.00$; and continuous). Since BMI is known to be positively associated with breast cancer risk in postmenopausal women, but inversely associated with risk in premenopausal women [9], we analyzed the interactions with BMI separately for women aged $<55$ years and $\geq 55$ years, considering these as a surrogates for pre- and post-menopausal status, respectively. Results from analyses using a younger age limit (50 years) to determine surrogate categories for premenopausal status were similar and are therefore not presented. Estimates of per-allele ORs for SNPs stratified by risk factors (for the categories defined above) were obtained using a single logistic regression model including appropriate dummy variables, in 
Table 2 Estimated per-allele odds ratios and $95 \%$ confidence intervals for 12 SNPs, by availability of non-genetic risk factor information*

\begin{tabular}{|c|c|c|c|c|c|c|c|c|}
\hline \multirow[t]{2}{*}{ SNP } & \multirow[t]{2}{*}{ Genes at locus } & \multirow[t]{2}{*}{ Alleles $^{\dagger}$} & \multirow[t]{2}{*}{$\mathrm{MAF}^{++}$} & \multirow{2}{*}{$\begin{array}{l}\text { OR }(95 \% \mathrm{Cl})^{\ddagger} \\
\text { All subjects }\end{array}$} & \multicolumn{4}{|c|}{ OR $(95 \% \mathrm{Cl})^{\ddagger \ddagger}$ based on subjects with data available on: } \\
\hline & & & & & Age menarche & Parity & Age at first birth & Body mass index" \\
\hline \multirow[t]{2}{*}{ 10q26-rs2981582 } & FGFR2 & $\mathrm{CT}$ & 0.38 & $1.22(1.19$ to 1.26$)$ & $1.22(1.19$ to 1.26$)$ & $1.22(1.19$ to 1.26$)$ & $1.22(1.18$ to 1.26$)$ & $1.21(1.17$ to 1.25$)$ \\
\hline & & & & $(25,821 / 22,551)$ & $(20,134 / 18,697)$ & $(21,985 / 20,111)$ & $(15,204 / 15,359)$ & $(16,883 / 18,660)$ \\
\hline \multirow[t]{2}{*}{ 8q24-rs13281615 } & intergenic & AG & 0.41 & $1.12(1.09$ to 1.15$)$ & $1.12(1.09$ to 1.16$)$ & $1.12(1.09$ to 1.16$)$ & $1.13(1.09$ to 1.17$)$ & $1.13(1.10$ to 1.17$)$ \\
\hline & & & & $(21,823 / 20,609)$ & $(16,779 / 16,698)$ & $(18,060 / 18,081)$ & $(11,808 / 13,610)$ & $(12,969 / 16,531)$ \\
\hline \multirow[t]{2}{*}{ 11p15-rs3817198 } & LSP1 & $\mathrm{TC}$ & 0.31 & $1.08(1.05$ to 1.11$)$ & 1.08 (1.05 to 1.12$)$ & 1.08 (1.05 to 1.11$)$ & 1.09 (1.05 to 1.13 ) & 1.08 (1.05 to 1.12$)$ \\
\hline & & & & $(25,004 / 21,596)$ & $(19,439 / 17,896)$ & $(21,268 / 19,249)$ & $(14,655 / 14,661)$ & $(16,191 / 17,810)$ \\
\hline \multirow[t]{2}{*}{ 5q11-rs889312 } & MAPЗK1 & $A C$ & 0.28 & 1.11 (1.08 to 1.15$)$ & 1.10 (1.06 to 1.13$)$ & 1.11 (1.07 to 1.14$)$ & 1.09 (1.05 to 1.13 ) & 1.09 (1.06 to 1.13$)$ \\
\hline & & & & $(26,227 / 23,307)$ & $(20,557 / 19,306)$ & $(22,407 / 20,855)$ & $(15,573 / 15,943)$ & $(17,304 / 19,335)$ \\
\hline \multirow[t]{2}{*}{ 16q12-rs3803662 } & TOX3/TNRC9 & $C \mathbf{T}$ & 0.26 & 1.23 (1.19 to 1.26$)$ & $1.22(1.18$ to 1.26$)$ & 1.24 (1.20 to 1.27$)$ & 1.21 (1.17 to 1.26$)$ & 1.23 (1.19 to 1.27$)$ \\
\hline & & & & $(26,132 / 23,459)$ & $(20,628 / 19,334)$ & $(22,478 / 20,874)$ & $(15,613 / 15,966)$ & $(17,356 / 19,351)$ \\
\hline \multirow[t]{2}{*}{ 2q35-rs13387042 } & intergenic & $\mathrm{GA}$ & 0.52 & 1.14 (1.11 to 1.17$)$ & 1.13 (1.10 to 1.16$)$ & 1.13 (1.11 to 1.16$)$ & 1.13 (1.10 to 1.17$)$ & 1.14 (1.11 to 1.18$)$ \\
\hline & & & & $(32,917 / 25,996)$ & $(26,581 / 21,507)$ & $(29,037 / 23,157)$ & $(23,757 / 17,897)$ & $(20,286 / 21,609)$ \\
\hline \multirow[t]{2}{*}{ 5p12-rs10941679 } & MRPS30 & AG & 0.26 & 1.12 (1.09 to 1.15$)$ & 1.13 (1.09 to 1.16$)$ & $1.12(1.08$ to 1.15$)$ & 1.13 (1.09 to 1.17$)$ & $1.12(1.08$ to 1.16$)$ \\
\hline & & & & $(31,513 / 25,008)$ & $(25,399 / 20,992)$ & $(27,436 / 22,456)$ & $(22,334 / 17,356)$ & $(18,568 / 20,370)$ \\
\hline \multirow[t]{2}{*}{ 17q23-rs6504950 } & COX11, STXBP4 & $\mathrm{GA}$ & 0.28 & 0.95 (0.92 to 0.97$)$ & 0.95 (0.92 to 0.98$)$ & 0.95 (0.92 to 0.97$)$ & 0.94 (0.91 to 0.98$)$ & 0.94 (0.91 to 0.97 ) \\
\hline & & & & $(30,045 / 23,943)$ & $(24,114 / 19,454)$ & $(26,246 / 21,094)$ & $(21,294 / 16,138)$ & $(17,497 / 19,500)$ \\
\hline \multirow[t]{2}{*}{ 3p24-rs4973768 } & SLC4A7, NEK10 & $C \mathbf{T}$ & 0.46 & 1.11 (1.09 to 1.14$)$ & 1.10 (1.07 to 1.13$)$ & 1.11 (1.08 to 1.14$)$ & 1.10 (1.07 to 1.14$)$ & 1.11 (1.08 to 1.14 ) \\
\hline & & & & $(30,366 / 22,929)$ & $(24,483 / 18,624)$ & $(26,707 / 20,292)$ & $(21,733 / 15,454)$ & $(17,892 / 18,618)$ \\
\hline \multirow[t]{2}{*}{ 2q33-rs17468277 } & CASP8 & $\mathrm{CT}$ & 0.13 & 0.94 (0.91 to 0.98 ) & 0.95 (0.91 to 0.99 ) & 0.96 (0.92 to 0.99$)$ & 0.94 (0.90 to 0.99$)$ & 0.96 (0.92 to 0.99 ) \\
\hline & & & & $(32,784 / 25,700)$ & $(26,702 / 21,218)$ & $(29,020 / 22,864)$ & $(23,718 / 17,637)$ & $(20,228 / 21,267)$ \\
\hline \multirow[t]{2}{*}{ 19q13-rs1982073 } & TGFB1 & $\mathrm{TC}$ & 0.38 & 1.04 (1.01 to 1.07$)$ & 1.04 (1.01 to 1.08$)$ & 1.04 (1.01 to 1.08$)$ & 1.05 (1.01 to 1.09$)$ & 1.04 (1.00 to 1.08$)$ \\
\hline & & & & $(24,498 / 17,003)$ & $(19,838 / 14,279)$ & $(20,424 / 14,950)$ & $(17,050 / 11,460)$ & $(11,849 / 13,586)$ \\
\hline \multirow[t]{2}{*}{ 6q25-rs3020314 } & ESR1 & $\mathrm{TC}$ & 0.32 & 1.03 (1.00 to 1.06$)$ & 1.02 (0.99 to 1.06$)$ & $1.02(0.99$ to 1.05$)$ & 1.02 (0.99 to 1.06$)$ & 1.01 (0.98 to 1.05$)$ \\
\hline & & & & $(24,009 / 20,496)$ & $(19,378 / 17,622)$ & $(20,623 / 18,515)$ & $(17,370 / 14,538)$ & $(15,505 / 17,167)$ \\
\hline
\end{tabular}

*The number of controls/cases (respectively) included in each analysis is given in square parenthesis.

${ }^{+}$Minor allele according to first publication in bold type.

${ }^{++}$Minor allele frequency, assessed in controls with available genotype data.

${ }^{\ddagger}$ Odds ratio per copy of the minor allele, adjusted for study (categorical), based on all genotype data, regardless of availability of non-genetic risk factor data.

${ }^{\ddagger \neq}$ Odds ratio per copy of the minor allele, adjusted for age (categorical: $\leq 34,35$ to 39,40 to 44,45 to 49,50 to 54,55 to 59,60 to 64,65 to 69,70 to $74, \geq 75$; and continuous), study and the corresponding nongenetic risk factor (continuous), based on data for subjects with genotype data and information on the non-genetic risk factor.

Model also included an interaction term for body mass index and age $(<55, \geq 55)$ 
addition to those for the main effects of the risk factor categories.

Interaction, or modification of genetic associations by other risk factors, was assessed for each SNP/risk factor combination by fitting logistic regression models. Each model included dummy variables for study plus three parameters, one for the main per-risk-allele effect, one for the main risk factor effect (all modeled as continuous variables, except ever having had a live birth) and a single interaction term for the product of the number of risk alleles and the value of the risk factor. This was tested statistically by a likelihood ratio test comparing this model to that without the interaction term. Effect modification by BMI was assessed separately for women $<55$ and $\geq 55$ years of age.

In addition, a parametric bootstrap test was used to estimate interaction $P$-values adjusted for multiple testing [15]. For each of the 72 interactions tested, we estimated the probability of being a case for each subject under the null hypothesis of no interaction, by applying the logistic regression model including only main effects for study (categorical), SNP (per-allele) and risk factor (continuous, except ever having had a live birth). Each replicate of the parametric bootstrap consisted of, for each interaction tested: (i) generating a dummy casecontrol status for each subject by sampling from a binomial distribution based on the estimated probability of being a case (by generating a single random number from the uniform distribution and assigning "case" to subjects for which this was less than the probability of being a case and "control" otherwise); and (ii) based on this dummy case-control status and the actual data for all other variables, fitting the interaction model described above and noting the likelihood ratio test $P$ value for the comparison of this model to the main effects only model applied to the same data. The minimum $P$-value was recorded for each of 10,000 replicates and the adjusted $P$-values were estimated as the proportion of replication $P$-values less than the corresponding unadjusted $P$-value. Results rounded to two decimal places were identical to those obtained using a standard non-parametric permutation test [15].

All statistical analyses were carried out using Stata: Release 10 (Statacorp, College Station, TX, USA) [16] with the exception of power calculations which were done using Quanto (University of Southern California, Los Angeles, CA, USA) [17,18].

\section{Results}

The 21 participating studies contributed 26,349 cases and 32,208 controls of self-reported white European race/ethnicity, all with available data for at least one of the 12 SNPs considered and at least one of the other risk factors considered (minimal data). Of these, 17,603 cases from 18 studies (all except BBCS, MCCS and USRT) were interviewed within two years after their breast cancer diagnosis and 29,187 controls came from the same 18 studies. Forty-six percent of cases and 38\% of controls were under age 55 years at diagnosis and interview, respectively. ER and PR status was known for 19,561 and 16,962 cases, respectively. Details by study are provided in Table 1 . In total, 12,822 cases and 19,703 controls with minimal data were included from 11 population-based studies and 16,107 cases and 23,140 controls with minimal data were included from seven studies with at least 1,000 cases and 1,000 controls.

When analyses were restricted to population-based studies, the expected associations with breast cancer were observed for the risk factors, with one exception. After adjustment for age and study, each one-year increase in age at menarche was associated with a $4 \%$ (95\% CI $=2$ to $5 \%$ ) decrease in breast cancer risk, and being parous was associated with a $16 \%$ (95\% CI $=10$ to $22 \%$ ) decreased risk. For parous women, each additional live birth was associated with an $11 \%$ (95\% CI $=8$ to $13 \%)$ decrease in risk, while each five-year increment in age at first birth was associated with a $7 \%(95 \% \mathrm{CI}=4$ to $10 \%)$ increase in risk. Obesity $\left(\mathrm{BMI} \geq 30.0 \mathrm{~kg} / \mathrm{m}^{2}\right)$ was associated with a $20 \%$ (95\% CI $=10$ to $29 \%$ ) lower risk of breast cancer for women under age 55 years. The one unexpected observation was that obesity was not associated with breast cancer risk in women aged 55 years and older (OR $=0.96,95 \%$ CI 0.88 to 1.04).

Table 2 provides estimated per-allele ORs and their 95\% CIs for the 12 SNPs considered, for all included subjects with genotype data, and for the subsets of women with information available for each of the four risk factors considered. All ORs were adjusted for study, and each subset was adjusted for study, age and the relevant risk factor. The OR estimates in the overall and subset analyses were very similar, and provide no evidence of confounding by the risk factors, nor of bias in OR estimates related to data availability.

For the vast majority of SNP/risk factor combinations, there was no evidence that the per-allele OR for the SNP varied by category of the risk factor. This was true for analyses based on data from all studies (Additional Data Table S2 in Additional file 1), for analyses based on population-based studies only (Additional Data Table S3 in Additional file 1) and for analyses based on the seven studies with at least 1,000 cases and 1,000 controls (Additional Data Table S4 in Additional file 1). Restricting analyses to the 18 studies with cases interviewed within two years after their breast cancer diagnosis made no substantial difference to the results obtained (data not shown). Similarly null results were observed for analyses restricted to ER-positive and 
ER-negative breast cancer (Additional Data tables S5 and S6 in Additional file 1) and for analyses restricted to PR-positive and PR-negative breast cancer (Additional Data Table S7 and S8 in Additional file 1).

The strongest evidence of interaction (unadjusted $P=0.002)$ was for the modification of the association with 11p15-rs3817198 (LSP1) by number of live births. Per-allele OR estimates increased from 1.04 (95\% CI = 0.97 to 1.11) for women who had had just one live birth to 1.24 (95\% CI $=1.11$ to 1.38$)$ for women with at least four live births, and an interaction OR of 1.05 per live birth and per allele was estimated. This trend was also observed when data from only populationbased studies and from only studies with at least 1,000 cases and 1,000 controls were considered $(P=0.01$ in both sub-analyses). Evidence for this interaction was observed when the analysis was restricted to ERpositive and PR-positive disease $(P=0.004$ and $P=$ 0.01 , respectively; Figure 1), but not for analyses based on ER-negative and PR-negative cases $(P=0.3$ and 0.06 , respectively). However, considering that 72 tests for interaction were carried out, chance cannot be excluded as an explanation for these results. The multiple-test-adjusted $P$-value for the modification of the $11 \mathrm{p} 15$-rs3817198 association by number of live births was 0.12 . The adjusted $p$-values for all other interactions tested were all $\geq 0.61$.

Post-hoc power calculations estimated that for age at menarche (per year), parity (per live birth) and age at first birth (per five-year age increase), our study had $90 \%$ power at a significance level of 0.0007 (corresponding to a multiple-testing-adjusted $P$-value of 0.05 ) to detect interaction ORs of at least 1.06 for all loci tested except CASP8-rs17468277, for which the minimum was 1.08. For BMI (per five-unit increase) the minimum interaction OR detectable with $90 \%$ power in both age strata $(<55$ and $\geq 55)$ was 1.08 for the more common variants and 1.10 for CASP8-rs17468277. For parity, considered as never or ever having had a live birth, the study had similar power to detect interaction ORs of at least 1.20 for CASP8-rs17468277 and 1.16 for the remaining loci.

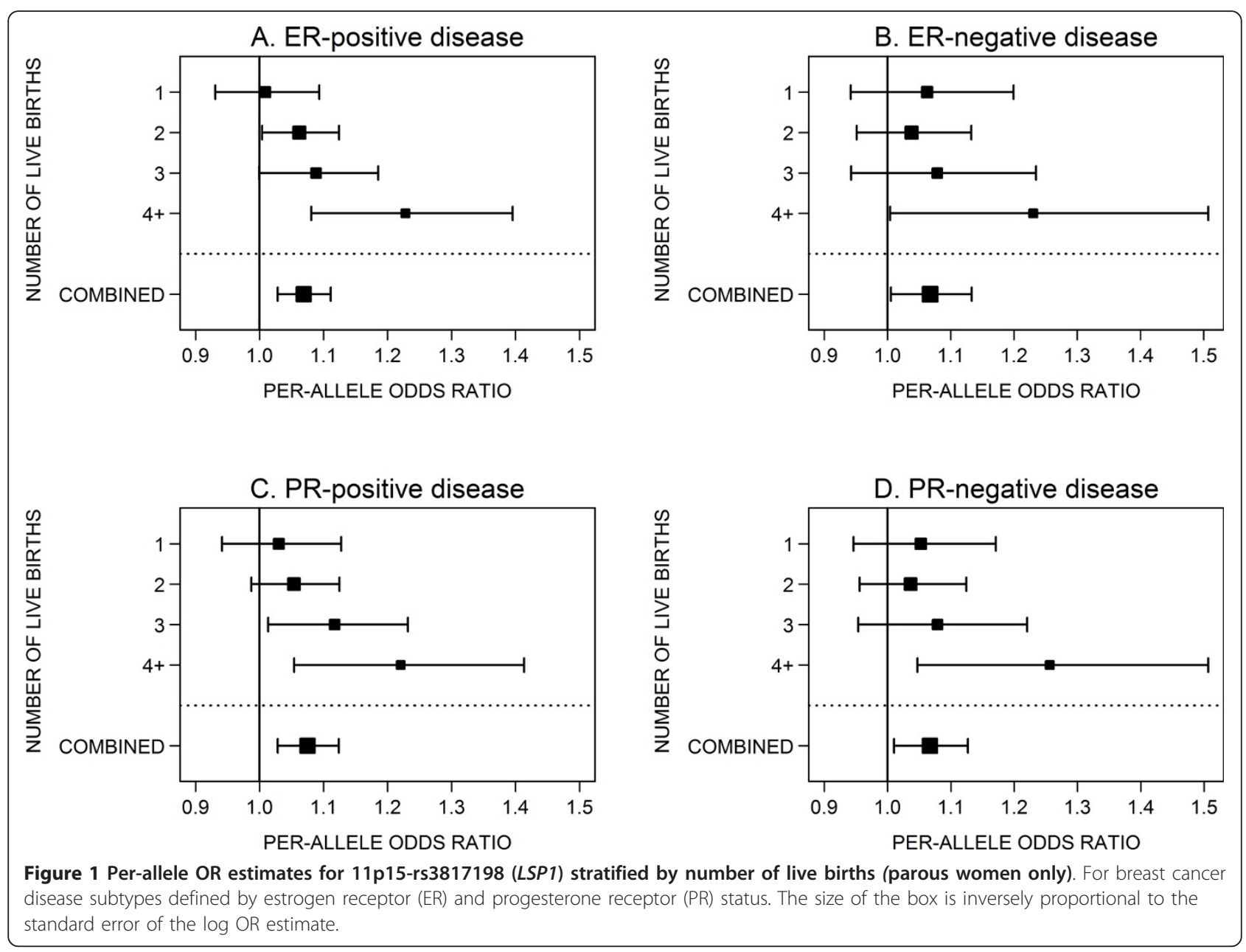




\section{Discussion}

This combined analysis of more than 25,000 cases and 30,000 controls found no conclusive evidence that age at menarche, parity, age at first birth or BMI modify the established associations of breast cancer risk with 10q26rs298158 (FGFR2), 8q24-rs13281615, 11p15-rs3817198 (LSP1), 5q11-rs889312 (MAP3K1], 16q12-rs2803662 (TOX3), 2q35-rs13387042, 5p12-rs10941679, 17q23rs6504950, 3p24-rs4973768 and CASP8-rs17468277) nor the putative associations with TGFB1-rs1982073 or ESR1rs3020314. This was also true for disease subtypes defined by ER and PR status.

The strongest evidence of effect modification was for number of live births and 11p15-rs3817198 (LSP1). However, the observed trend of increasing relative risk with increasing parity was not statistically significant after correction for multiple testing. It should be noted that the interaction OR was 1.05 per allele and per live birth. This corresponds to an estimated per-allele OR increasing from 1.04 for women with one child to 1.24 for women with four or more children, for a SNP with an estimated average OR of 1.08 across all levels of parity. Such weak interactions would only result in very small differences in estimates of joint effects relative to those from models assuming multiplicative effects. This finding in this very large study highlights the difficulty of identifying modifying effects of this magnitude.

A recent study by Travis et al. of 7,610 cases and 10,196 controls reported null results for interactions in breast cancer susceptibility between 9 of the same genetic loci and 10 risk factors, including age at menarche, parity, age at first birth and BMI [19]. Our null findings replicate the results from this prospective study of older women (over age 50 years), but in a study with more than twice the sample size in this age group, and confirm that they are also applicable to women under age 50 years. Our study also extends the genetic loci evaluated for interactions with a subset of established breast cancer risk factors to include 17q23rs6504950 and 3p24-rs4973768 [1] and ESR1-rs3020314 [7], which were not considered by Travis et al. [19]. Furthermore, with regard to the susceptibility locus at 5 p12, we considered the more strongly associated SNP rs10941679 rather than rs981782 (which is only weakly correlated with rs10941679) [5]. Of note, Travis et al. found no evidence of interaction between 11p15rs3817198 (LSP1) and number of children $(P=0.9)$ [19].

One of the strengths of the BCAC is the large combined sample size achieved through international collaboration. This has proven to be very effective in confirming or ruling out association with breast cancer for common SNPs identified through GWAS and candidate gene studies $[1,2,6,14,20,21]$. The BCAC has also been able to provide highly precise estimates of the ORs associated with susceptibility alleles, with very high consistency observed between the many studies that participate in the consortium, despite the range of study designs represented. The inclusion of multiple studies that recruited selected cases and/or volunteer controls means that the main effects for some risk factors cannot be appropriately evaluated across the whole consortium. However, this potential selection bias in estimating main effects should not influence the assessment of interactions [22]. Nevertheless, we carried out sensitivity analyses considering only data from population-based studies and only data from studies with at least 1,000 cases and 1,000 controls and observed no substantial change in the results obtained regarding interactions. We also performed analyses of the full dataset, allowing for between-study heterogeneity in the main effects for the risk factors by including interaction terms for each, and similarly observed that this did not influence the results obtained (data not shown).

A potential limitation of our study derives from heterogeneity in data collection methods across studies. All studies except two (neither population-based) used structured questionnaires administered by a variety of means, including in-person interviews, phone-interviews and self-administration. Nevertheless, the measurement of age at menarche, ever having had a live birth, number of live births and age at first birth seem likely to be robust to these differences in data collection method. Our results for BMI may be more likely to be affected by heterogeneity in data collection methods, although standardized measurement within studies and adjustment for study as a covariate should limit this to a loss of power, rather than any systematic bias. We repeated our primary analyses excluding cases interviewed before, or more than two years after, their breast cancer diagnosis and results were not substantially different. This suggests that between-study differences in the reference time at which BMI was reported did not influence the inference from our study. A further limitation of our study was that we did not collate information on hormone therapy (HT) use from the majority of participating studies and so were unable evaluate interactions between SNPs and BMI by HT use in older women. This requires further investigation because $\mathrm{HT}$ has been observed to modify the effect of obesity on post-menopausal breast cancer risk [23]. Since menopausal status was not assessed and/or derived uniformly across all studies, we used age as a surrogate to more appropriately stratify analyses of effect modification by BMI. Finally, the present study had limited statistical power to detect interactions in susceptibility to ER-negative and PR-negative disease. 


\section{Conclusions}

In summary, in the largest collaborative analyses of gene-environment interactions carried out to date, we have observed no conclusive evidence for modification of the per-allele relative risk associated with common breast cancer susceptibility variants by age at menarche, parity, age at first birth or BMI. This finding is consistent with those from a recently published smaller prospective study. These results imply that the combined effects of these common susceptibility alleles and other established risk factors can be assumed to multiplicative in risk predicted models for breast cancer.

\section{Additional material}

\section{Additional file 1: Additional data tables S1 to S8. Additional Data}

Table 1: Design details for each study. Additional Data Table 2: Per-allele breast cancer odds ratios (OR) estimates and 95\% confidence intervals (ORlower, ORupper) for SNPs, stratified by age at menarche, ever having had a live birth, number of live births, age at first birth and BMl; based on data from all studies. Additional Data Table 3: Per-allele breast cancer odds ratio (OR) estimates and $95 \%$ confidence intervals (ORlower ORupper) for SNPs, stratified by age at menarche, ever having had a live birth, number of live births, age at first birth and BMl; based on data from population-based studies only. Additional Data Table 4: Per-allele breast cancer odds ratio (OR) estimates and 95\% confidence intervals (ORlower, ORupper) for SNPs, stratified by age at menarche, ever having had a live birth, number of live births, age at first birth and BMl; based on data only from studies with at least 1,000 cases and 1,000 controls. Additional Data Table 5: Per-allele ER-positive breast cancer odds ratios (OR) and 95\% confidence intervals (ORlower, ORupper) for SNPs, stratified by age at menarche, ever having had a live birth, number of live births, age at first birth and BMI; based on data from all studies. Additional Data Table 6: Per-allele ER-negative breast cancer odds ratios (OR) and 95\% confidence intervals (ORlower, ORupper) for SNPs, stratified by age at menarche, ever having had a live birth, number of live births, age at first birth and BMI; based on data from all studies. Additional Data Table 7: Per-allele PR-positive breast cancer odds ratios (OR) and 95\% confidence intervals (ORlower, ORupper) for SNPs, stratified by age at menarche, ever having had a live birth, number of live births, age at first birth and BMI; based on data from all studies. Additional Data Table 8: Per-allele PRnegative breast cancer odds ratios (OR) and $95 \%$ confidence intervals (ORlower, ORupper) for SNPs, stratified by age at menarche, ever having had a live birth, number of live births, age at first birth and BMl; based on data from all studies.

\section{Abbreviations}

ABCFS: Australian Breast Cancer Family Study; AOCS: Australian Ovarian Cancer Study; BBCC: Bavarian Breast Cancer Cases and Controls; BBCS: British Breast Cancer Study; BCAC: Breast Cancer Association Consortium; BMI: body mass index; CEPH, Centre d'Etude Polymorphisme Humain; CGPS: Copenhagen General Population Study; Cl: confidence interval; CNIO-BCS: Spanish National Cancer Centre Breast Cancer Study; ER: estrogen receptor; GENICA: Gene Environment Interaction \& Breast Cancer in Germany; GESBC Genetic Epidemiology Study of Breast Cancer by Age 50; GWAS: genomewide association study; HT: hormone therapy; KBCP: Kuopio Breast Cancer Project; kConFab: Kathleen Cuningham Foundation Consortium for Research into Familial Breast Cancer; LMBC: Leuven Multidisciplinary Breast Centre; MARIE: Mammary Carcinoma Risk Factor Investigation; MCBCS: Mayo Clinic Breast Cancer Study; MCCS: Melbourne Collaborative Cohort Study; NC-BCFR: Northern California Breast Cancer Family Registry; OFBCR: Ontario Familial Breast Cancer Registry; OR: odds ratio; PBCS: NCI Polish Breast Cancer Study; PR: progesterone receptor; SASBAC: Singapore and Sweden Breast Cancer Study; SBCS: Sheffield Breast Cancer Study; SEARCH: Study of Epidemiology and Risk factors in Cancer Heredity; SNP: single nucleotide polymorphism; UCIBCS: UCI Breast Cancer Study; USA: United States of America; USRT: US Radiologic Technologists Study.

\section{Acknowledgements}

We thank all the individuals who took part in these studies and all the researchers, clinicians, technicians and members of the administrative staff who have enabled this work to be carried out. In particular, we thank: Charo Alonso, Toni Picornell, David Pisano, Eduardo Andrés, Eva Barroso, Iñaki De Blas Méndez and Primitiva Menéndez (CNIO-BCS); Eileen Williams and Elaine Ryder-Mills (BBCS); Stephen Chanock (PBCS; National Cancer Institute, USA), Neonila Szeszenia-Dabrowska and Beata Peplonska (PBCS; Nofer Institute of Occupational Medicine, Lodz, Poland), Witold Zatonski (PBCS; M. SklodowskaCurie Cancer Center and Institute of Oncology, Warsaw, Poland), Pei Chao and Michael Stagner (PBCS; Information Management Services, Sliver Spring MD, USA); Margaret McCredie (ABCFS); Jerry Reid (USRT; American Registry of Radiologic Technologists), Laura Bowen (USRT), Diane Kampa and Allison Iwan (USRT; University of Minnesota); Helena Kemiläinen, Aija Parkkinen and Eija Myöhänen (KBCP); Helen Cramp, Dan Connley, Sue Higham, lan Brock, Saba Balasubramanian and Graeme Elliott (SBCS); Christina Justenhoven, Ute Hamann, Christian Baisch, Hans-Peter Fischer, Beate Pesch, Volker Harth and Sylvia Rabstein (GENICA); Gilian Peuteman, Dominiek Smeets, Sofie Van Soest and Kathleen Corthouts (LMBC); Ursula Eilber, Belinda Kaspereit and Tanya Koehler (GESBC); Heather Thorne, Eveline Niedermayr and the Family Cancer Clinics (kConFab), the kConFab team and the kConFab Clinical Follow Up Study (funded 2001-2009 by NHMRC and currently by the National Breast Cancer Foundation and Cancer Australia \#628333); D Bowtell, G ChenevixTrench, A deFazio, D Gertig, A Green, P Webb (AOCS Management Group); Mary Karaus, Catie Erding and Xianshu Wang (MCBCS); Tracy Slanger, Elke Mutschelknauss, S. Behrens, R. Birr, W. Busch, U. Eilber, B. Kaspereit, N. Knese, K. Smit and the pathology institutes (MARIE); the SEARCH team, Caroline Baynes, Craig Luccarini and Don Conroy (SEARCH).

Part of this work was supported by the European Community's Seventh Framework Programme under grant agreement number 223175 (HEALTHF2-2009-223175). The CNIO-BCS work was partly funded by the Red Temática de Investigación Cooperativa en Cáncer, the Asociación Española Contra Cáncer and grants from the Fondo de Investigación Santiario (PI081583 to RLM and PI081120 to JB). The BBCS is funded by Cancer Research UK and Breakthrough Breast Cancer and acknowledges NHS funding to the NIHR Biomedical Research Centre, and the National Cancer Research Network (NCRN). The PBCS was funded by Intramural Research Funds of the National Cancer Institute, Department of Health and Human Services, USA. The UCIBCS is supported by the National Institutes of Health, National Cancer Institute grants CA-58860, CA-92044 and the Lon V Smith Foundation grant LVS-39420. The ABCFS, NC-BCFR and OFBCR work was supported by the United States National Cancer Institute, National Institutes of Health (NIH) under RFA-CA-06-503 and through cooperative agreements with members of the Breast Cancer Family Registry (BCFR) and Principal Investigators, including Cancer Care Ontario (U01 CA69467), Northern California Cancer Center (U01 CA69417), University of Melbourne (U01 CA69638). Samples from the NC-BCFR were processed and distributed by the Coriell Institute for Medical Research. The content of this manuscript does not necessarily reflect the views or policies of the National Cancer Institute or any of the collaborating centers in the BCFR, nor does mention of trade names, commercial products, or organizations imply endorsement by the US Government or the BCFR. The ABCFS was also supported by the National Health and Medical Research Council of Australia, the New South Wales Cancer Council, the Victorian Health Promotion Foundation (Australia) and the Victorian Breast Cancer Research Consortium. JLH is a National Health and Medical Research Council (NHMRC) Australia Fellow and a Victorian Breast Cancer Research Consortium Group Leader. MCS is a NHMRC Senior Research Fellow and a Victorian Breast Cancer Research Consortium Group Leader. The USRT study was supported by the Intramural Research Program of the Division of Cancer Epidemiology and Genetics, National Cancer Institute, National Institutes of Health. The KBCP is supported by EVO funds from Kuopio University Hospital and Vaasa Central Hospital, and grants from the Academy of Finland and the Finnish Cancer Foundation. The SBCS was supported by Yorkshire Cancer Research and the Breast Cancer Campaign. The GENICA Network was funded by the Federal Ministry of Education and Research (BMBF) Germany grants 01KW9975/5, 01 KW9976/8, 01 KW9977/0 and 01KW0114, the Robert Bosch Foundation of Medical Research, Stuttgart, 
Deutsches Krebsforschungszentrum (DKFZ) Heidelberg, Institute for Prevention and Occupational Medicine of the German Social Accident Insurance (IPA), Bochum, as well as the Department of Internal Medicine, Evangelische Kliniken Bonn gGmbH, Johanniter Krankenhaus, Bonn, Germany. The LMBC is supported by European Union Framework Programme 6 Project LSHC-CT-2003-503297 (the Cancerdegradome) and by the 'Stichting tegen Kanker' (232-2008). The GESBC was supported by the Deutsche Krebshilfe e. V. (70492), with genotyping partly funded by the state of Baden-Württemberg through the Medical Faculty of the University of UIm (P.685). The kConFab is supported by grants from the National Breast Cancer Foundation, the NHMRC and by the Queensland Cancer Fund, the Cancer Councils of New South Wales, Victoria, Tasmania and South Australia, and the Cancer Foundation of Western Australia. Financial support to the AOCS was provided by the U.S. Army Medical Research and Materiel Command under DAMD17-01-1-0729, the Cancer Council Tasmania and Cancer Foundation of Western Australia. ABS and GCT are Senior and Senior Principal Research Fellows, respectively, of the NHMRC. The MCCS was funded by grants from the NHMRC $(251533,209057,504711)$ and was further supported by infrastructure provided by The Cancer Council Victoria. The CGPS was supported by the Chief Physician Johan Boserup and Lise Boserup Fund, the Danish Medical Research Council and Copenhagen University Hospital, Herlev Hospital. The MCBCS was supported by NIH grant CA122340 and the NIH breast cancer specialized program of research excellence (CA116201). The MARIE study was supported by the Deutsche Krebshilfe e.V., grant number 70-2892-BR I, the Hamburg Cancer Society and the German Cancer Research Center. The BBCC was partly funded by the ELAN Program of the University Hospital of Erlangen. P.A.F. was funded by the Dr. Mildred Scheel Foundation of the Deutsche Krebshilfe. SASBAC was supported by funding from the Agency for Science, Technology and Research of Singapore (A*STAR), the NIH and the Susan G. Komen Breast Cancer Foundation. The Breast Cancer Association Consortium and SEARCH are funded by grants from Cancer Research UK. DFE is a Cancer Research UK Principal Research Fellow. None of these funding bodies had any role in the analysis or interpretation of data, in the writing of the manuscript or in the decision to submit the manuscript for publication.

\section{Author details}

${ }^{1}$ Genetic and Molecular Epidemiology Group, Human Cancer Genetics Programme, Spanish National Cancer Research Centre (CNIO), Melchor Fernández Almagro 3, Madrid, 28029, Spain. ${ }^{2}$ Departments of Epidemiology and Population Health \& of Obstetrics \& Gynecology and Women's Health, Albert Einstein College of Medicine, 1300 Morris Park Ave., New York, NY 10461, USA. ${ }^{3}$ Queensland Institute of Medical Research, 300 Herston Road, Brisbane, 4006, Australia. ${ }^{4}$ Division of Hematology and Oncology, David Geffen School of Medicine, University of California at Los Angeles, 10833 Le Conte Avenue, Los Angeles, CA 90024, USA. ${ }^{5}$ Department of Laboratory Medicine and Pathology, Mayo Clinic, 200 First Street S.W., Rochester, MN 55905, USA. 'Human Genetics Group, Human Cancer Genetics Programme, CNIO, Melchor Fernández Almagro 3, Madrid, 28029, Spain. ${ }^{7}$ Servicio de Cirugía General y Especialidades, Hospital Monte Naranco, Avda. Dres. Fernández-Vega 9, Oviedo, 33012, Spain. ${ }^{8}$ Servicio de Oncología Médica, Hospital Universitario La Paz, Paseo de la Castellana 261, Madrid, 28046, Spain. ${ }^{9}$ Department of Epidemiology and Population Health, London School of Hygiene and Tropical Medicine, Keppel St., London, WC1E 7HT, UK ${ }^{10}$ Breakthrough Breast Cancer Research Centre, The Institute of Cancer Research, 237 Fulman Road, London, SW36JB, UK. ${ }^{11}$ Department of Epidemiology, School of Medicine, UC Irvine, 224 Irvine Hall, Irvine, CA 92697, USA. ${ }^{12}$ Division of Cancer Epidemiology and Genetics, Hormonal and Reproductive Epidemiology Branch, National Cancer Institute, 6120 Executive Blvd, Rockville, MD 20852, USA. ${ }^{13}$ Department of Cancer Epidemiology and Prevention, The M. Sklodowska-Curie Cancer Center and Institute of Oncology, ul Roentgena 5, Warsaw, 02 781, Poland. ${ }^{14}$ Centre for Molecular, Environmental, Genetic and Analytic Epidemiology, The University of Melbourne, Level 1, 723 Swanston Street, Melbourne, 3010, Australia. ${ }^{15}$ Department of Pathology, The University of Melbourne, 5th floor, West Wing, Medical Building 181, Melbourne, 3010, Australia. ${ }^{16}$ Radiation Epidemiology Branch, Division of Cancer Epidemiology and Genetics, National Cancer Institute, Executive Plaza South, Room 7094, Bethesda, MD 20892, USA. ${ }^{17}$ Institute of Clinical Medicine, Department of Pathology, University of Eastern Finland, Yliopistonranta 1, Kuopio, 70210, Finland. ${ }^{18}$ Department of Pathology, Kuopio University Hospital, Harjulantie 1, Kuopio,
70210, Finland. ${ }^{19}$ Biocenter Kuopio, Yliopistonranta 1, Kuopio, 70211, Finland. ${ }^{20}$ Department of Oncology, Kuopio University Hospital, Harjulantie 1, Kuopio, 70210, Finland. ${ }^{21}$ Department of Oncology, Vaasa Central Hospital, Hietalahdenkatu 2-4, Vaasa, 65130, Finland. ${ }^{22}$ Samuel Lunenfeld Research Institute, Mount Sinai Hospital, 600 University Ave., Toronto, ON, M5G 1X5, Canada. ${ }^{23}$ Ontario Cancer Genetics Network, Cancer Care Ontario, 620 University Avenue, Toronto, ON M5G 2C1, Canada. ${ }^{24}$ Departments of Molecular Genetics and Laboratory Medicine and Pathobiology, University of Toronto, 1 King's College Circle, Toronto, ON M5S 1A8, Canada. ${ }^{25}$ Dalla Lana School of Public Health, University of Toronto, 155 College Street, Toronto, ON M5T 3M7, Canada. ${ }^{26}$ Institute for Cancer Studies, Department of Oncology, University of Sheffield Medical School, Western Bank, Sheffield, S10 2TN, UK. ${ }^{27}$ Academic Unit of Surgical Oncology, Department of Oncology, University of Sheffield Medical School, Western Bank, Sheffield, S10 2TN, UK. ${ }^{28}$ Academic Unit of Pathology, Department of Neuroscience, University of Sheffield Medical School, Western Bank, Sheffield, S10 2TN, UK ${ }^{29}$ Department of Oncology, University of Cambridge, Strangeways Research Laboratory, Wort's Causeway, Cambridge, CB1 8RN, UK. ${ }^{30}$ Dr. Margarete Fischer-Bosch-Institute of Clinical Pharmacology, Auerbach Str. 112, Stuttgart, 70367, Germany and University Tübingen, Wachterstrasse, Tübingen, 72074, Germany. ${ }^{31}$ Department of Internal Medicine, Evangelische Kliniken Bonn gGmbH, Johanniter Krankenhaus, Johanniterstraße 3, Bonn, 53113, Germany. ${ }^{32}$ Institute for Prevention and Occupational Medicine of the German Social Accident Insurance (IPA), Bürkle-de-la-Camp Platz 1, Bochum, 44789, Germany. ${ }^{33}$ Molecular Genetics of Breast Cancer, Deutsches Krebsforschungszentrum (DKFZ), Im Neuenheimer Feld 280, Heidelberg, 69120, Germany. ${ }^{34}$ Institute of Pathology, Medical Faculty University of Bonn, Reuterstr. 2b, Bonn, 53113, Germany. ${ }^{35}$ Vesalius Research Center (VRC), VIB and KULeuven, Herestraat 49 B, Leuven, 3000 Belgium. ${ }^{36}$ Multidisciplinary Breast Center, University Hospital Gasthuisberg, Herestraat 49 B, Leuven, 3000, Belgium. ${ }^{37}$ Department of Obstetrics and Gynecology, University of Ulm, Prittwitzstrasse 43. Ulm, 89075, Germany. ${ }^{38}$ Department of Medical Epidemiology and Biostatistics, Karolinska Institutet, Nobels väg 12A, Stockholm, SE-171 77, Sweden. ${ }^{39}$ Human Genetics, Genome Institute of Singapore, 60 Biopolis Street, Genome, \#02-01, Singapore, 138672, Singapore. ${ }^{40}$ Kathleen Cuningham Foundation Consortium for Research into Familial Breast Cancer, Peter MacCallum Cancer Center, St Andrews PI, Melbourne, 3002, Australia. ${ }^{41}$ Australian Ovarian Cancer Study Group, Peter MacCallum Cancer Center, St Andrews Pl, Melbourne, 3002, Australia. ${ }^{42}$ Cancer Epidemiology Centre, Cancer Council Victoria, 1 Rathdowne St, Melbourne, 3053, Australia. ${ }^{43}$ Department of Epidemiology and Preventive Medicine, Monash University, Level 6 The Alfred Centre, 99 Commercial Road, Melbourne, 3004, Australia. ${ }^{44}$ Department of Clinical Biochemistry and Department of Breast Surgery, Herlev Hospital, Copenhagen University Hospital, Herlev Ringvej 75, Herlev, 2730, Denmark. ${ }^{45}$ Cancer Prevention Institute of California, 2201 Walnut Avenue, Suite 300, Fremont, CA 94538, USA. ${ }^{46}$ Stanford University School of Medicine, 300 Pasteur Drive, Stanford, CA 94305, USA. ${ }^{47}$ Department of Health Sciences Research, Mayo Clinic, 200 First Street S.W. Rochester, MN 55905, USA. ${ }^{48}$ Division of Cancer Epidemiology, German Cancer Research Center (DKFZ), Im Neuenheimer Feld 280, Heidelberg, 69120, Germany. ${ }^{49}$ Institute for Medical Biometrics and Epidemiology, University Clinic Hamburg-Eppendorf, Martinistrasse 52, Hamburg, 20246, Germany. ${ }^{50}$ Department of Gynecology and Obstetrics, University Hospital Erlangen, Universitätsstrasse 21 23, Erlangen, 91054 Germany. ${ }^{51}$ Institute of Human Genetics, Friedrich Alexander University Erlangen-Nuremberg, Schlossplatz 4, Erlangen, 91054, Germany.

${ }^{52}$ Department of Public Health and Primary Care, University of Cambridge, Strangeways Research Laboratory, Wort's Causeway, Cambridge, CB1 8RN, UK.

\section{Authors' contributions}

RLM performed the statistical analyses and wrote the manuscript. MMG also carried out statistical analyses. RLM, MMG, ABS, PAF, FJC, PDP, MGC, ELG and JCC formed part of the writing group which was responsible for the interpretation of results and critical revision of the manuscript for important intellectual content. JB, NM, IdSS, OF, NJ, JF, JLH, MCS, AJS, MSL, SJS, DMF, VMK, PA, ILA, GG, JAK, HB, DL, PH, KC, JJL, GCT, LB, GS, SEB, EMJ, RH, MWB, $\mathrm{LH}$ and DFE also contributed to the interpretation of results and/or critical revision of the manuscript. RLM, PAF, FJC, JB, JIAP, MPZ, IdSS, LJG, HAC, AZ, LB, MES, JL, JLH, GSD, CA, MCS, AJS, MSL, DMF, VK, ILA, GG, JAK, NW, AC, MWRR, SSC, MS, AMD, HB, YDK, TB, GENICA, DL, AS, PH, JJL, GCT, KConFab, 
AOCS, GGG, LB, GS, SEB, BGN, HF, EMJ, DWW, ASW, CV, JEO, ZF, AV, DFJ, JH, $\mathrm{KH}, \mathrm{LH}, \mathrm{MKH}, J \mathrm{M}, \mathrm{DFE}, \mathrm{PDP}, \mathrm{MGC}$ and JCC participated in the original design, subject recruitment, acquisition of data and/or biospecimen collection for the studies that contributed data. RLM, MMG, OF, NJ, AZ, MCS, AJS, SJS, AM, ILA, AC, AMD, SA, HB, GENICA, DL, JR, SWG, AKI, HH, SEB, BGN, ZF, MK, ABE, $\mathrm{MKH}$ and JM carried out the genotyping and/or quality control of genotype and other data. All authors were involved in drafting the manuscript and read and approved the final version.

\section{Competing interests}

The authors declare that they have no competing interests.

Received: 25 August 2010 Revised: 17 November 2010

Accepted: 31 December 2010 Published: 31 December 2010

\section{References}

1. Ahmed S, Thomas G, Ghoussaini M, Healey CS, Humphreys MK, Platte R, Morrison J, Maranian M, Pooley KA, Luben R, Eccles D, Evans DG, Fletcher O, Johnson N, dos Santos Silva I, Peto J, Stratton MR, Rahman N, Jacobs K, Prentice R, Anderson GL, Rajkovic A, Curb JD, Ziegler RG, Berg CD, Buys SS, McCarty CA, Feigelson HS, Calle EE, Thun MJ, et al: Newly discovered breast cancer susceptibility loci on $3 p 24$ and 17q23.2. Nat Genet 2009, 41:585-590

2. Easton DF, Pooley KA, Dunning AM, Pharoah PD, Thompson D, Ballinger DG, Struewing JP, Morrison J, Field H, Luben R, Wareham N, Ahmed S, Healey CS, Bowman R, the SEARCH collaborators, Meyer KB, Haiman CA, Kolonel LK, Henderson BE, Le Marchand L, Brennan P, Sangrajrang S, Gaborieau V, Odefrey F, Shen CY, Wu PE, Wang HC, Eccles D, Evans DG, Peto J, et al: Genome-wide association study identifies novel breast cancer susceptibility loci. Nature 2007, 447:1087-1093.

3. Hunter DJ, Kraft P, Jacobs KB, Cox DG, Yeager M, Hankinson SE, Wacholder S, Wang Z, Welch R, Hutchinson A, Wang J, Yu K, Chatterjee N, Orr N, Willett WC, Colditz GA, Ziegler RG, Berg CD, Buys SS, McCarty CA, Feigelson HS, Calle EE, Thun MJ, Hayes RB, Tucker M, Gerhard DS, Fraumeni JF Jr, Hoover RN, Thomas G, Chanock SJ: A genome-wide association study identifies alleles in FGFR2 associated with risk of sporadic postmenopausal breast cancer. Nat Genet 2007, 39:870-874

4. Stacey SN, Manolescu A, Sulem P, Rafnar T, Gudmundsson J, Gudjonsson SA, Masson G, Jakobsdottir M, Thorlacius S, Helgason A, Aben KK, Strobbe L, Albers-Akkers MT, Swinkels DW, Henderson BE, Kolonel LN, Le Marchand L, Millastre E, Andres R, Godino J, Garcia-Prats MD, Polo E, Tres A, Mouy M, Saemundsdottir J, Backman VM, Gudmundsson L, Kristjansson K, Bergthorsson JT, Kostic J, et al: Common variants on chromosomes $2 \mathrm{q} 35$ and $16 \mathrm{q} 12$ confer susceptibility to estrogen receptor-positive breast cancer. Nat Genet 2007, 39:865-869.

5. Stacey SN, Manolescu A, Sulem P, Thorlacius S, Gudjonsson SA, Jonsson GF, Jakobsdottir M, Bergthorsson JT, Gudmundsson J, Aben KK, Strobbe LJ, Swinkels DW, van Engelenburg KC, Henderson BE, Kolonel LN, Le Marchand L, Millastre E, Andres R, Saez B, Lambea J, Godino J, Polo E, Tres A, Picelli S, Rantala J, Margolin S, Jonsson T, Sigurdsson H, Jonsdottir T, Hrafnkelsson J, et al: Common variants on chromosome $5 \mathrm{p} 12$ confer susceptibility to estrogen receptor-positive breast cancer. Nat Genet 2008, 40:703-706.

6. Cox A, Dunning AM, Garcia-Closas M, Balasubramanian S, Reed MW, Pooley KA, Scollen S, Baynes C, Ponder BA, Chanock S, Lissowska J, Brinton L, Peplonska B, Southey MC, Hopper JL, McCredie MR, Giles GG, Fletcher O, Johnson N, dos Santos Silva I, Gibson L, Bojesen SE, Nordestgaard BG, Axelsson CK, Torres D, Hamann U, Justenhoven C, Brauch $\mathrm{H}$, Chang-Claude J, Kropp S, et al: A common coding variant in CASP8 is associated with breast cancer risk. Nat Genet 2007, 39:352-358.

7. Dunning AM, Healey CS, Baynes C, Maia AT, Scollen S, Vega A, Rodriguez R, Barbosa-Morais NL, Ponder BA, Low YL, Bingham S, Haiman CA, Le Marchand L, Broeks A, Schmidt MK, Hopper J, Southey M, Beckmann MW Fasching PA, Peto J, Johnson N, Bojesen SE, Nordestgaard B, Milne RL, Benitez J, Hamann U, Ko Y, Schmutzler RK, Burwinkel B, Schurmann P, et al: Association of ESR1 gene tagging SNPs with breast cancer risk. Hum Mol Genet 2009, 18:1131-1139.

8. Kelsey JL, Gammon MD, John EM: Reproductive factors and breast cancer. Epidemiol Rev 1993, 15:36-47.

9. van den Brandt PA, Spiegelman D, Yaun SS, Adami HO, Beeson L, Folsom AR, Fraser G, Goldbohm RA, Graham S, Kushi L, Marshall JR,
Miller AB, Rohan T, Smith-Warner SA, Speizer FE, Willett WC, Wolk A, Hunter DJ: Pooled analysis of prospective cohort studies on height, weight, and breast cancer risk. Am J Epidemiol 2000, 152:514-527.

10. Pharoah PD, Antoniou AC, Easton DF, Ponder BA: Polygenes, risk prediction, and targeted prevention of breast cancer. N Engl J Med 2008, 358:2796-2803

11. Wacholder S, Hartge P, Prentice R, Garcia-Closas M, Feigelson HS, Diver WR, Thun MJ, Cox DG, Hankinson SE, Kraft P, Rosner B, Berg CD, Brinton LA, Lissowska J, Sherman ME, Chlebowski R, Kooperberg C, Jackson RD, Buckman DW, Hui P, Pfeiffer R, Jacobs KB, Thomas GD, Hoover RN, Gail MH, Chanock SJ, Hunter DJ: Performance of common genetic variants in breast-cancer risk models. N Engl J Med 2010, 362:986-993.

12. Garcia-Closas M, Hall P, Nevanlinna H, Pooley K, Morrison J, Richesson DA, Bojesen SE, Nordestgaard BG, Axelsson CK, Arias Jl, Milne RL, Ribas G, Gonzalez-Neira A, Benitez J, Zamora P, Brauch H, Justenhoven C, Hamann U, Ko YD, Bruening T, Haas S, Dork T, Schurmann P, Hillemanns P, Bogdanova N, Bremer M, Karstens JH, Fagerholm R, Aaltonen K, Aittomaki K, et al: Heterogeneity of breast cancer associations with five susceptibility loci by clinical and pathological characteristics. PLoS Genet 2008, 4: e1000054.

13. Althuis MD, Fergenbaum JH, Garcia-Closas M, Brinton LA, Madigan MP, Sherman ME: Etiology of hormone receptor-defined breast cancer, a systematic review of the literature. Cancer Epidemiol Biomarkers Prev 2004, 13:1558-1568.

14. Milne RL, Benitez J, Nevanlinna H, Heikkinen T, Aittomaki K, Blomqvist C, Arias JI, Zamora MP, Burwinkel B, Bartram CR, Meindl A, Schmutzler RK, Cox A, Brock I, Elliott G, Reed MW, Southey MC, Smith L, Spurdle AB, Hopper JL, Couch FJ, Olson JE, Wang X, Fredericksen Z, Schurmann P, Bremer M, Hillemanns P, Dork T, Devilee P, van Asperen CJ, et al: Risk of estrogen receptor-positive and -negative breast cancer and singlenucleotide polymorphism 2q35-rs13387042. J Natl Cancer Inst 2009, 101:1012-1018

15. Buzkova P, Lumley T, Rice K: Permutation and parametric bootstrap tests for gene-gene and gene-environment interactions. Ann Hum Genet 2011, 75:36-45.

16. StataCorp: Stata Statistical Software: Release 10.0 College Station, Texas (USA): Stata Corporation LP; 2007.

17. Gauderman W: Sample size requirements for association studies of genegene interaction. Am J Epidemiol 2002, 155:478-484.

18. QUANTO 1.1: A computer program for power and sample size calculations for genetic-epidemiology studies. [http://hydra.usc.edu/gxe].

19. Travis RT, Reeves GK, Green J, Bull D, Tipper SJ, Baker K, Beral V, Peto R, Bell J, Zelenika D, Lathrop M, Million Women Study Collaborators: Geneenvironment interactions in 7610 women with breast cancer: prospective evidence from the Million Women Study. Lancet 2010, 375:2143-2151.

20. Breast Cancer Association Consortium: Commonly studied singlenucleotide polymorphisms and breast cancer: results from the Breast Cancer Association Consortium. J Natl Cancer Inst 2006, 98:1382-1396.

21. Gaudet MM, Milne RL, Cox A, Camp NJ, Goode EL, Humphreys MK, Dunning AM, Morrison J, Giles GG, Severi G, Baglietto L, English DR, Couch FJ, Olson JE, Wang X, Chang-Claude J, Flesch-Janys D, Abbas S, Salazar R, Mannermaa A, Kataja V, Kosma VM, Lindblom A, Margolin S, Heikkinen T, Kampjarvi K, Aaltonen K, Nevanlinna H, Bogdanova N, Coinac I, et al: Five polymorphisms and breast cancer risk: results from the Breast Cancer Association Consortium. Cancer Epidemiol Biomarkers Prev 2009, 18:1610-1616.

22. Morimoto $L M$, White $E$, Newcomb PA: Selection bias in the assessment of gene-environment interaction in case-control studies. Am J Epidemiol 2003, 158:259-263

23. Lahmann PH, Hoffmann $\mathrm{K}$, Allen $\mathrm{N}$, van Gils $\mathrm{CH}$, Khaw $\mathrm{KT}$, Tehard $\mathrm{B}$, Berrino F, Tjonneland A, Bigaard J, Olsen A, Overvad K, Clavel-Chapelon F, Nagel G, Boeing H, Trichopoulos D, Economou G, Bellos G, Palli D, Tumino R, Panico S, Sacerdote C, Krogh V, Peeters PH, Bueno-deMesquita HB, Lund E, Ardanaz E, Amiano P, Pera G, Quiros JR, Martinez C, et al: Body size and breast cancer risk: findings from the European Prospective Investigation into Cancer And Nutrition (EPIC). Int J Cancer 2004, 111:762-771

24. Dite GS, Jenkins MA, Southey MC, Hocking JS, Giles GG, McCredie MR, Venter DJ, Hopper JL: Familial risks, early-onset breast cancer, and BRCA1 and BRCA2 germline mutations. J Natl Cancer Inst 2003, 95:448-457. 
25. Fasching PA, Loehberg CR, Strissel PL, Lux MP, Bani MR, Schrauder M, Geiler S, Ringleff K, Oeser S, Weihbrecht S, Schulz-Wendtland R, Hartmann A, Beckmann MW, Strick R: Single nucleotide polymorphisms of the aromatase gene (CYP19A1), HER2/neu status, and prognosis in breast cancer patients. Breast Cancer Res Treat 2008, 112:89-98.

26. Schrauder M, Frank S, Strissel PL, Lux MP, Bani MR, Rauh C, Sieber CC, Heusinger K, Hartmann A, Schulz-Wendtland R, Strick R, Beckmann MW, Fasching PA: Single nucleotide polymorphism D1853N of the ATM gene may alter the risk for breast cancer. J Cancer Res Clin Oncol 2008, 134:873-882.

27. Johnson N, Fletcher O, Naceur-Lombardelli C, dos Santos Silva Ashworth A, Peto J: Interaction between CHEK2*1100delC and other lowpenetrance breast-cancer susceptibility genes: a familial study. Lancet 2005, 366:1554-1557.

28. Bojesen SE, Tybjaerg-Hansen A, Axelsson CK, Nordestgaard BG: No association of breast cancer risk with integrin beta3 (ITGB3) Leu33Pro genotype. Br J Cancer 2005, 93:167-171.

29. Weischer M, Bojesen SE, Tybjaerg-Hansen A, Axelsson CK, Nordestgaard BG: Increased risk of breast cancer associated with CHEK2*1100delC. J Clin Oncol 2007, 25:57-63.

30. Milne RL, Ribas G, Gonzalez-Neira A, Fagerholm R, Salas A, Gonzalez E, Dopazo J, Nevanlinna H, Robledo M, Benitez J: ERCC4 associated with breast cancer risk: a two-stage case-control study using high-throughput genotyping. Cancer Res 2006, 66:9420-9427.

31. Justenhoven C, Pierl CB, Haas S, Fischer HP, Baisch C, Hamann U, Harth V, Pesch B, Bruning T, Vollmert C, Illig T, Dippon J, Ko YD, Brauch H: The CYP1B1_1358_GG genotype is associated with estrogen receptornegative breast cancer. Breast Cancer Res Treat 2008, 111:171-177.

32. Chang-Claude J, Eby N, Kiechle M, Bastert G, Becher H: Breastfeeding and breast cancer risk by age 50 among women in Germany. Cancer Causes Control 2000, 11:687-695.

33. Hartikainen JM, Tuhkanen $H$, Kataja V, Dunning AM, Antoniou A, Smith $P$, Arffman A, Pirskanen M, Easton DF, Eskelinen M, Uusitupa M, Kosma VM, Mannermaa A: An autosome-wide scan for linkage disequilibrium-based association in sporadic breast cancer cases in eastern Finland: three candidate regions found. Cancer Epidemiol Biomarkers Prev 2005, 14:75-80.

34. Mann GJ, Thorne H, Balleine RL, Butow PN, Clarke CL, Edkins E, Evans GM, Fereday S, Haan E, Gattas M, Giles GG, Goldblatt J, Hopper JL, Kirk J, Leary JA, Lindeman G, Niedermayr E, Phillips KA, Picken S, Pupo GM, Saunders C, Scott CL, Spurdle AB, Suthers G, Tucker K, Chenevix-Trench G: Analysis of cancer risk and BRCA1 and BRCA2 mutation prevalence in the kConFab familial breast cancer resource. Breast Cancer Res 2006, 8 R12.

35. Beesley J, Jordan SJ, Spurdle AB, Song H, Ramus SJ, Kjaer SK, Hogdall E, DiCioccio RA, McGuire V, Whittemore AS, Gayther SA, Pharoah PD, Webb PM, Chenevix-Trench G: Association between single-nucleotide polymorphisms in hormone metabolism and DNA repair genes and epithelial ovarian cancer: results from two Australian studies and an additional validation set. Cancer Epidemiol Biomarkers Prev 2007, 16:2557-2565.

36. De Maeyer L, Van Limbergen E, De Nys K, Moerman P, Pochet $N$, Hendrickx W, Wildiers H, Paridaens R, Smeets A, Christiaens MR, Vergote I, Leunen K, Amant F, Neven P: Does estrogen receptor negative/ progesterone receptor positive breast carcinoma exist? J Clin Oncol 2008, 26:335-336, author reply 336-338.

37. Neven P, Brouckaert O, Van Belle V, Vanden Bempt I, Hendrickx W, Cho H, Deraedt K, Van Calster B, Van Huffel S, Moerman P, Amant F, Leunen K, Smeets A, Wildiers H, Paridaens R, Vergote I, Christiaens MR: In early-stage breast cancer, the estrogen receptor interacts with correlation between human epidermal growth factor receptor 2 status and age at diagnosis, tumor grade, and lymph node involvement. J Clin Oncol 2008, 26:1768-1769, author reply 1769-1771

38. Flesch-Janys D, Slanger T, Mutschelknauss E, Kropp S, Obi N, Vettorazzi E, Braendle W, Bastert G, Hentschel S, Berger J, Chang-Claude J: Risk of different histological types of postmenopausal breast cancer by type and regimen of menopausal hormone therapy. Int J Cancer 2008, 123:933-941.

39. Olson JE, Ma CX, Pelleymounter LL, Schaid DJ, Pankratz VS, Vierkant RA, Fredericksen ZS, Ingle JN, Wu Y, Couch F, Sellers TA, Weinshilboum RM, Vachon CM: A comprehensive examination of CYP19 variation and breast density. Cancer Epidemiol Biomarkers Prev 2007, 16:623-625.
40. Giles GG, English DR: The Melbourne Collaborative Cohort Study. IARC Sci Publ 2002, 156:69-70.

41. John EM, Hopper JL, Beck JC, Knight JA, Neuhausen SL, Senie RT, Ziogas A, Andrulis IL, Anton-Culver H, Boyd N, Buys SS, Daly MB, O'Malley FP, Santella RM, Southey MC, Venne VL, Venter DJ, West DW, Whittemore AS, Seminara D: The Breast Cancer Family Registry: an infrastructure for cooperative multinational, interdisciplinary and translational studies of the genetic epidemiology of breast cancer. Breast Cancer Res 2004, 6: R375-389.

42. Garcia-Closas M, Brinton LA, Lissowska J, Chatterjee N, Peplonska B, Anderson WF, Szeszenia-Dabrowska N, Bardin-Mikolajczak A, Zatonski W, Blair A, Kalaylioglu Z, Rymkiewicz G, Mazepa-Sikora D, Kordek R, Lukaszek S, Sherman ME: Established breast cancer risk factors by clinically important tumour characteristics. Br J Cancer 2006, 95:123-129.

43. Wedren S, Lovmar L, Humphreys K, Magnusson C, Melhus H, Syvanen AC, Kindmark A, Landegren U, Fermer ML, Stiger F, Persson I, Baron J, Weiderpass E: Oestrogen receptor alpha gene haplotype and postmenopausal breast cancer risk: a case control study. Breast Cancer Res 2004, 6:R437-449.

44. MacPherson G, Healey CS, Teare MD, Balasubramanian SP, Reed MW Pharoah PD, Ponder BA, Meuth M, Bhattacharyya NP, Cox A: Association of a common variant of the CASP8 gene with reduced risk of breast cancer. J Natl Cancer Inst 2004, 96:1866-1869.

45. Lesueur F, Pharoah PD, Laing S, Ahmed S, Jordan C, Smith PL, Luben R, Wareham NJ, Easton DF, Dunning AM, Ponder BA: Allelic association of the human homologue of the mouse modifier Ptprj with breast cancer. Hum Mol Genet 2005, 14:2349-2356.

46. Anton-Culver $\mathrm{H}$, Cohen PF, Gildea ME, Ziogas A: Characteristics of BRCA1 mutations in a population-based case series of breast and ovarian cancer. Eur J Cancer 2000, 36:1200-1208.

47. Ziogas A, Gildea M, Cohen P, Bringman D, Taylor TH, Seminara D, Barker D Casey G, Haile R, Liao SY, Thomas D, Noble B, Kurosaki T, Anton-Culver H: Cancer risk estimates for family members of a population-based family registry for breast and ovarian cancer. Cancer Epidemiol Biomarkers Prev 2000, 9:103-111.

48. Sigurdson AJ, Bhatti $\mathrm{P}$, Chang SC, Rajaraman P, Doody MM, Bowen L, Simon SL, Weinstock RM, Linet MS, Rosenstein M, Stovall M, Alexander BH, Preston DL, Struewing JP: Polymorphisms in estrogen biosynthesis and metabolism-related genes, ionizing radiation exposure, and risk of breast cancer among US radiologic technologists. Breast Cancer Res Treat 2009, 118:177-184.

doi: $10.1186 / \mathrm{bcr} 2797$

Cite this article as: Milne et al:: Assessing interactions between the associations of common genetic susceptibility variants, reproductive history and body mass index with breast cancer risk in the breast cancer association consortium: a combined case-control study. Breast Cancer Research 2010 12:R110.

\section{Submit your next manuscript to BioMed Central and take full advantage of:}

- Convenient online submission

- Thorough peer review

- No space constraints or color figure charges

- Immediate publication on acceptance

- Inclusion in PubMed, CAS, Scopus and Google Scholar

- Research which is freely available for redistribution

Submit your manuscript at www.biomedcentral.com/submit
C Biomed Central 